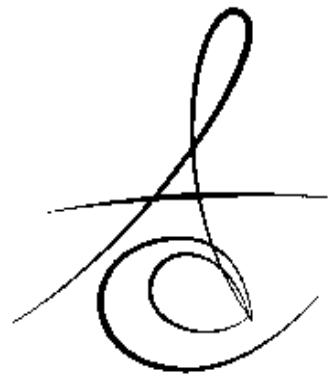

Makale Kodu/Article code: 2756

Makale Gönderilme tarihi: 30.03.2016

Kabul Tarihi: 13.05.2016

\section{HALİTOZİSIN YENİDEN SINIFLANDIRILMASI VE UYGUN TEŞHİS YÖNTEMLERİ}

\author{
RE-CLASSIFICATION AND PROPER DIAGNOSTIC METHODS OF \\ HALITOSIS
}

\author{
Doç. Dr. Özkan MİLOĞLU* \\ Yrd. Doç. Dr. Alper ÖZDOĞAN ${ }^{* *}$
}

öz

Ağız kokusu nefes yoluyla yayılan kötü koku olarak tanımlanır. Kötü koku ağızdaki besin maddelerinin ya da diğer artıkların bakteriler tarafından yıkılmasından ve kötü ağız hijyeninden kaynaklanır. Uçucu sülfür bileşikleri, oral malodorun önde gelen unsurlarıdır. Ağız kokusunun prevalansı dünyada \%22 ile \%50 arasındadır. Koku multifaktöriyel etiyolojiye sahiptir, lokal faktörler vakaların çoğunda önemli bir rol oynamaktadır. Dil dorsumu ağız kokusunun en önemli kaynağıdır. Halitozis değerlendirmesi organoleptik ölçümler, sülfür monitörü, gaz kromatografisi kullanılarak yapılabilir. Doğru bir teşhis yapmak, hastalığın nedenlerini belirlemek ve hasta tedavisi için uygun adımlar atmak önemlidir. Tedavi altta yatan sebebe yönelik olmalıdır.

$\mathrm{Bu}$ derlemede ağız kokusunun intraoral ve ekstraoral nedenleri, güncel sınıflandırması ve teşhis yöntemleri, tedavisindeki güncel yaklaşımlar ile ilgili bilgi verilmeye çalışılmıştır.

Anahtar Kelimeler: Halitozis, ağız kokusu, prevalans, sınıflandırma, teşhis yöntemleri, tedavi, uçucu sülfür bileşikleri

\section{GİRIŞ}

Ağız kokusu halitozis, oral malodor, fetor exore, fetor oris, bad breath olarak da adlandırılır. ${ }^{1}$ Halitozis ağız içi veya ağız dışı nefes yoluyla çıkan kötü koku olarak tanımlanmaktadır. ${ }^{2}$ Günlük hayatta diş hekimleri ağız kokusundan etkilenen hastaların ilk

\section{ABSTRACT}

Halitosis is defined as the bad odor emitted through the breathing. Bad odor is caused by bacteria from the decay of food particles, other debris in the mounth, and poor oral hygiene. Volatile sulphur compounds are the prominent elements of oral malodour. The prevalence of halitosis is between $22 \%$ and $50 \%$ in the world. Halitosis has a multifactorial etiology, local factors play an important role in the majority of cases. The dorsum of the tongue is the most important source of halitosis. Assessment of halitosis can be performed using organoleptic measurements, sulfide monitoring, gas chromatography. It is important to make a correct diagnosis, identify the causes of the disease and to take appropriate steps in order to cure the patient. Treatment is directed at the underlying cause.

In this review, it is aimed to give information about intraoral and extraoral causes of halitosis, current classification and diagnosis methods, current approaches to the treatment.

Keywords: Halitosis, prevalence, classification, diagnostic methods, treatment, volatile sulphur compounds

başvurduğu kişilerdir. ${ }^{3}$ Ağız kokusu teşhisinde hastanın şikâyetleri ve hastanın çevresinden gelen bildirimler önemlidir. Halitozisin prevalansı \%22-50 gibi yüksek bir oranda rapor edilmektedir ve etkilenen kişilerde önemli sosyal ve psikolojik sıkıntılara neden olmaktadır. ${ }^{4}$ Kuzey Amerika halkının \%50'sinden fazlasının halitozisten şikâyetçi olduğu tahmin edilmektedir. ${ }^{5}$

\footnotetext{
* Atatürk Üniversitesi, Diş Hekimliği Fakültesi, Ağız, Diş ve Çene Radyolojisi Anabilim Dalı, Erzurum

** Atatürk Üniversitesi, Diş Hekimliği Fakültesi, Protetik Diş Tedavisi A nabilim Dall, Erzurum

Bu çalışmanın bir kısmı 18-20 Mart 2016 tarihinde Erzurum'da yapılmıs olan 5. Uluslararası TPİD Palandöken Kış Sempozyumu'nda poster sunumu şeklinde paylaşıımıştır.
} 
Japon toplumunda \%6-23 oranında sosyal olarak kabul edilebilir sınırların üzerinde ağız kokusu olduğunu rapor edilmiştir. ${ }^{6}$ Cinsiyetin halitozisin prevalans ve şiddeti açısından bir fark oluşturmadığı rapor edilmiştir. Farklı yaş grupları incelendiğinde ise kokuya sebep olan VSB (Volatil sülfür bileşikleri) değerlerinin yaşa bağlı olarak arttığı belirtilmiştir. ${ }^{7}$

Farklı ağız kokuları aynı zamanda kişinin sağlık durumu hakkında bilgi veren önemli bir faktördür.

Tablo 1. Çeşitli hastalıklar ve kötü kokuların özellikleri ${ }^{8}$

\begin{tabular}{|l|l|}
\hline Hastalık & Ağız kokusunun özelliği \\
\hline Diabetes mellitus & $\begin{array}{l}\text { Aseton kokusu, tatımsı meyve } \\
\text { kokusu }\end{array}$ \\
\hline Karaciğer yetmezliği & $\begin{array}{l}\text { Amin kokusu, küf kokusu, taze } \\
\text { ölü kokulu nefes }\end{array}$ \\
\hline Akut romatizmal ateş & Tatlımsı asit kokusu \\
\hline Akciğer absesi & Çürüme kokusu \\
\hline Karaciğer sirozu & Bozulmuş kan kokusu \\
\hline Üremi & Amonyak kokusu, idrar kokusu \\
\hline $\begin{array}{l}\text { Toksemia, gastrointestinal ve } \\
\text { nöropsikiyatrik bozukluk }\end{array}$ & Çeşitlidir \\
\hline $\begin{array}{l}\text { Ateş, dehidratasyon, } \\
\text { makroglobulinemi }\end{array}$ & Kötü kokulu nefes \\
\hline Sjögren's sendromu & Bozuk pis kokulu nefes \\
\hline $\begin{array}{l}\text { Eosinofilik granuloma, Letter-Siwe } \\
\text { hastalığı, Hand-Schuller-Christian } \\
\text { hastalığı }\end{array}$ & Bozuk pis kokulu nefes \\
\hline Skorbüt & Kötü kokulu nefes \\
\hline Wegener's granulomatosis & Yara benzeri çürüme kokusu \\
\hline Böbrek yetmezliği & Amonyak üre kokusu \\
\hline $\begin{array}{l}\text { Difteri, dizanteri, } \\
\text { pnömoni, kızıl, tüberküloz }\end{array}$ & Pis ve kötü kokulu nefes \\
\hline Sifiliz & Pis kokulu nefes \\
\hline
\end{tabular}

\section{SINIFLANDIRMA}

Terminolojide evrensel bir sınıflandırma ve tanım olmamasına rağmen kaynaklarda farklı şekillerde ele alınabilen bir konudur. ${ }^{7}$ Genel olarak halitozis primer ve sekonder olarak ayrılmaktadır. Primer halitozis akciğerlerden yapılan solunumdan kaynaklanırken, sekonder halitozis ağız ve üst solunum yollarından kaynaklanmaktadır. ${ }^{9}$ Klinik halitozis ise gerçek halitozis, pseudohalitozis ve halitofobi (Olfactory Reference Sendrom) olarak sınıflandırılmaktadır. Gerçek halitozis ise kendi içinde fizyolojik ve patolojik olarak incelenmektedir. Patolojik halitozis de oral veya ekstraoral kaynaklı olabilmektedir., ${ }^{9,10}$

Psödohalitozis ağız kokusu olmadığı halde bundan yakınan hastalar için kullanılan terimdir. Halitofobi ise ağız kokusu korkusu olan hastalar için kullanımaktadır. ${ }^{9}$

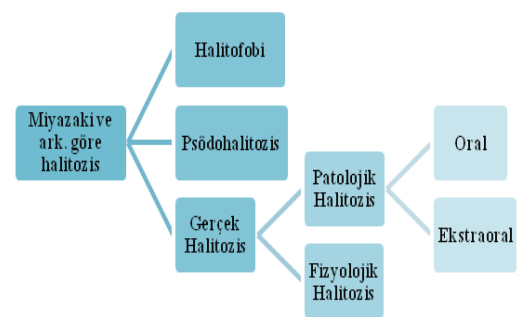

Tablo 2. Miyazaki ve ark. ${ }^{11}$ göre halitozis sınıflandırması, 1999.

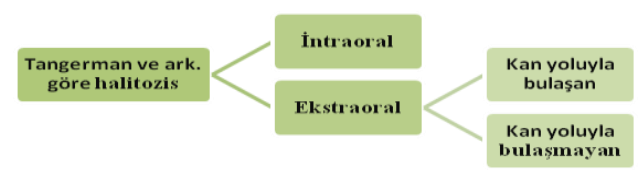

Tablo 3. Tangerman ve Winkel' $\mathrm{e}^{12}$ göre halitozis sınıflandırması, 2010.

Son dönemdeki güncel bilgilere göre halitozis tip 1: Oral, tip 2: Havayolu, tip 3: Gastroözofageal, tip 4: Patolojik (kan yoluyla), tip 5: Sübjektif, tip 0: Fizyolojik şeklinde de sınıflandırılabilmektedir. ${ }^{13}$

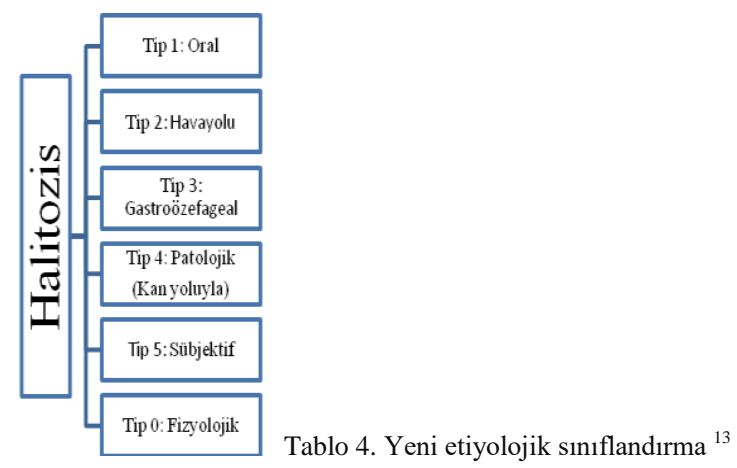

Genel sınıflandırma dışında terminolojide geçen bazı terimler de mevcuttur. Gece uykusundan sonra görülen durum 'Morning Breath' olarak adlandırılır. ${ }^{14,15}$ Ağız kokusu problemi yaşan insanların tam olarak bu durumun farkında olmamalarından dolayı tedavi için diş hekimine başvurmamaları 'Koku Paradoksu' olarak adlandırılır. ${ }^{16}$ Parosmia, yoktan koku algılama, olmayan bir kokuyu hissetme ile belirgin duyu bozukluğudur. Cacosmia, mevcut olmadığı halde hoşa gitmeyen kokular hissetme halidir. Anosmia, koku alma hissinin olmayışıdır. ${ }^{17}$ Disosmia, koku alma duyusundaki yetersizliktir. Hyperosmia, koku alma duyusunun ileri derece keskin oluşudur. ${ }^{17}$ Hypereuosmia, güzel ve kötü kokuları birbirinden ayıramama durumudur.

Klinik olarak halitozisten şikâyetçi olan bazı hastalarda gerçekten ağız kokusu varken diğerlerinde

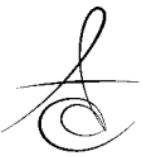


hemen hemen hiçbir koku yoktur. Bu durum 'Psikosomatik Halitozis' olarak adlandırımaktadır. Ben-Aryeh ve arkadaşları $^{18}$ da halitozis şikâyetiyle başvuran hastalarının; organoleptik metotla \%43'ünde, sülfit monitörü ile \%39'unda halitozis bulamamışlardır.

\section{HALİTOZİS NEDENLERİ}

Ağız kokusu multifaktöriyel etiyolojiye sahiptir, lokal faktörler vakaların çoğunda önemli bir rol oynamaktadır. ${ }^{19}$

\section{Ağız Kaynaklı Nedenler}

Ağız kokusu temel olarak oral kavitenin durumu ile alakalıdır. Delanghe ve arkadaşları ${ }^{20}$ halitozisin yaklaşık \%87'sinin sebebinin ağız içi kaynaklı olduğunu rapor etmişlerdir. Bunlardan \%51'i dilden, \%17'si gingivitisten, \%15 periodontitisten, \%17'si bunların karışımından kaynak alır. ${ }^{17}$

Ağız kaynaklı nedenler genel olarak periodontal hastalıklar, implant hastalıkları, çürükler, nekrotik diş pulpaları, mukozal ülserler, kirli protezler, hijyenik olmayan köprü gövdeleri, hatalı restorasyonlar, yirmi yaş perikoroniti, salivasyon azlığı, besin artıklarının varlığı, aft yaraları, dental apseler, herpetik infeksiyonlar, kandidiazis, ağız kanserleri, xerestomia, kötü ağız hijyeni, peritonsiller apse, ağız solunumu, ağızdaki bütün cilaSIz yüzeyler, dilin dorsalinin plakla kaplanması(dilin geniş yüzey alanı, papiller yapısı, düzensiz ve derin fissürlü yüzeyi) olarak gösterilebilir. 9,14,21-24 Aynı zamanda $\mathrm{pH}^{\prime \prime \prime n ~ y u ̈ k s e l m e s i ~ d e ~ a g ̆ z ı ~ k o k u s u n u ~ k o l a y l a s ̧ t ı r ı r ~}$ ve arttırır. ${ }^{10}$

\section{Ağız Dışı Nedenler}

Oral olmayan sebeplerle ortaya çıkan ağız kokusunun görülme sıklığı ise \%13'tür. Bunların \%4'ü kulak-burun-boğaz, \%3'ü hem oral hem kulak-burunboğaz, \%1'i ise sindirim kanalı kaynaklıdır. ${ }^{17}$ Delanghe ve arkadaşlarının ${ }^{20}$ yaptığı çalışmaların sonucunda ise hastaların sadece \%5-8'inde kulak-burun-boğaz sorunları halitozis için sebep olarak belirtilmiştir.

Ağız dışı nedenler genel olarak sistemik hasta Iıklar, alınan ilaçlar ve gıdalar olarak sınıflandırılabilir. Bunlara örnek olarak; burun ve sinüsler, tonsiller, farenks ve sindirim organlarındaki patolojik ya da fizyolojik bozukluklar, vitamin ve mineral eksikliği(A vitamini, $B_{12}$ vitamini, demir veya çinko eksikliği), diabetik ketoasidoz, karaciğer yetmezliği, böbrek yetmezliği, üremi, radyasyon tedavisi, Sjögren sendromu, bazı ak- ciğer hastalıkları, Von Willebrand hastalığı, Helicobacter pylori, gastroözofageal reflü, aplastik anemi, lösemi, trombositopeni gibi kanamalı hastalıklar, difteri, kızamık, pnömoni, sifiliz, euzinofilik granüloma ve Lettere-Siwe gibi hastalıklar, yüksek ateş, ilaçların çökelmesi, sigara, açlık ve stres gösterilebilir. ${ }^{9,21,25-29}$

Aynı zamanda anksiyete, depresyon gibi psikolojik faktörler ve stres gibi bazı kişilik özellikleri sübjektif ağız kokusu için risk faktörü olarak kabul edilebilir. $^{30}$

\section{HALİTOZİSİN OLUŞUM MEKANİZMASI}

Genelde ağız kokusunun temel biyokimyasal nedeni bakteriyel çürüme ve bakteriler tarafından proteinlerin yıkılması ile çeşitli aminoasitler ve diğer bileşiklerin ortaya çıkmasıdır. Ağızda bu ortamın oluşmasında tükürük en önemli rolü oynar. ${ }^{31,32}$ Halitoziste dilin dorsumu, tükürük ve periodontal cepler bakteriyel rezervuar görevi görmektedir. ${ }^{33}$ Bakterilerin metabolik reaksiyonları sırasında açığa çıkan ve kokuya neden olan maddelerin başında uçucu sülfür bileşikleri (VSB) gelmektedir. $\mathrm{Bu}$ uçucu sülfür bileşikleri esasen hidrojen sülfit $\left(\mathrm{H}_{2} \mathrm{~S}\right)$, dimetil sülfit $\left(\mathrm{CH}_{3} \mathrm{SCH}_{3}\right)$ ve metil merkaptan $\left(\mathrm{CH}_{3} \mathrm{SH}\right)$ olarak dikkat çekmektedir. ${ }^{34,35}$ Yapılan araştırmalar sonucu sisteinli gargaraların ağız kokusunu arttırdığının belirlenmesi bu bileşiğin ağız kokusunun en önemli kaynağı olduğunu göstermiştir. Ağız kokusu ile ilgili olarak diğer kükürtlü bileşikler daha az etkilidir.

Uçucu sülfür bileşiklerinden kaynaklanan ağız kokusu için en önemli kaynak bölgenin dil olduğu belirlenmiştir. Özellikle dilin dorsoposterior bölgesinden kaynaklanmaktadır. ${ }^{36,37}$ Bu bölge dilin en geniş yüzeyli bölgesidir. Ayrıca dilin 2/3 arka kısmında bulunan, tat tomurcukları ve dil papilleri arasına biriken bakteriler salyanın yıkayıcı etkisinden gizlenebilmektedir. Dil ucundan, dil köküne gidildikçe VSB konsantrasyonu artmaktadır. ${ }^{17}$ Oho ve arkadaşları ${ }^{38}$ halitozis pozitif olan grupta, negatif olan gruba göre dil örtüsünün daha kalın olduğunu belirtmişlerdir.

Yapılan araştırmalarda tükürük beta-galaktosidaz faaliyeti ile kötü koku da ilişkilendirilmiştir ve tükürük beta-galaktosidaz faaliyetinin kötü koku üretiminde önemli rol oynadığı görülmüştür. Aynı zamanda beta-galaktosidaz aktivitesiyle plak indeksi ve dil kaplama puanı da ilişkilidir. ${ }^{39}$

Klinik çalışmalarda halitozis ile sondlamada 
kanama, sondlama derinliği ve periodontal patojenler arasında ilişki tespit edilmiştir. ${ }^{40}$ Periodontal hastalık esnasında, periodontal cepteki bakteri kolonizasyonunun daha da arttığı ve VSB oluşmasında önemli bir göreve sahip olduğu tespit edilmiştir. ${ }^{22}$

Mikroflora belirleme çalışmalarında ağızdaki 300'ün üzerinde bakteri türü arasından ağız kokusu ile ilgili olanları izole edilmiştir. Bu araştırmalar sonucunda Fusobacterium nucleatum, Veillonella, Tannerella forsythensis, Treponema denticola, Porphyromonas gingivalis, Prevotella intermedia gibi gr (-) bakteri grubunun sebep olduğu putrefaksiyonun ağız kokusu etkeni olduğu kabul edilmektedir. ${ }^{41-43}$ Ayrıca protez- lerde kötü kokuya sebep olan Klebsiella ve Entrobacterium'un invitro deneylerde kadaverin ve uçucu sülfür bileşikleri yaparak kötü koku yaydığı belirlenmiştir. $^{44}$

Ağız dışı nedenlerle oluşan halitozisin mekanizmasında genel olarak ağız solunumu yapılması, tükürük bezlerinin etkilenmesi ve ağız kuruluğuyla birlikte yine uçucu sülfür bileşikleri rol oynamaktadır. Gastroözofageal reflü gibi durumlarda ağız ortamının asiditesindeki değişimden dolayı halitozis görülebilmektedir. Diğer sistemik hastalıklarda ise alınan ilaçların etkisiyle ağız içi mikroflora değişiminden kaynaklı ağız kokusu görülebilmektedir.

\section{TEŞHİS TEKNİKLERİ}

Gaz moleküllerinin karmaşıklığı, örnekleme zorlukları, zamansal değişimler, referans standartlar üstünde anlaşma eksikliği teşhisi zorlaştırır. Psikofiziksel değerlendirmelerde hassasiyet insandan insana değişebilir. Ayrıca ağız kokusunun şiddetinin intraoral VSB seviyesi ile ilişkili olduğu gösterilmiştir. Bu yüzden gaz kromatografisiyle uçucu sülfür bileşiklerini değerlendirmek daha güvenilirdir. ${ }^{1}$ Fosnick ve arkadaşları 1950'lerde kokunun kaynağını ölçen bir alet olan Osmocopy'i geliştirene kadar bilimsel olarak bu konu üzerinde çalışılmamıştır. ${ }^{7}$

Halitozis teşhis teknikleri organoleptik ölçüm, gaz kromatografi (GC) ve sülfid monitörü olarak 3 ana metot şeklinde ele alınır.

Organoleptik Ölçüm: Hastalar ölçümü yapan hekimin burnundan yaklaşık $10 \mathrm{~cm}$ uzaklıktan ağızlarına yerleştirilen $2,5 \mathrm{~cm}$ çapındaki bir tüp vasıtasıyla nefes verirler. ${ }^{45}$ Buna ilaveten bu metotta hasta kendi bileğini yalar, yalanan yerin kuruması beklenir ve kok- lanır. İnterdental plak tespitinde mumsuz diş ipi kulanıIır ve $3 \mathrm{~cm}$ mesafeden koklanarak değerlendirme yapılır. Kokunun dil kaynaklı olup olmadığını değerlendirmek için ise dilin yüzeyinden plastik bir kaşık ile kazıma yapılır ve testi yapan kişinin burnuna 5 cm uzakta kalacak şekilde değerlendirme yapılır.

Bu ölçümde (0-5) skalası koku için uygunluk skalası olarak kullanılmaktadır. Bu skalada $0=$ koku yok, 1=zor belirlenebilir koku, 2=hafif fakat net belirlenebilir koku, 3=orta şiddette koku, 4=güçlü kötü koku, 5=aşırı kötü koku olarak kabul edilir. ${ }^{46}$ Organoleptik değerlendirme ağız kokusu teşhisinde referanstır. ${ }^{47}$

Ağız kokusunu daha objektif olarak değerlendirmek için ise gaz kromatografi ve portable sülfit monitörü geliştirilmiştir. Oho ve arkadaşları ${ }^{38}$ organoleptik test, gaz kromatografi ve sülfit monitörü ile elde edilen sonuçlar arasında önemli bir korelasyon bulmuşlardır. Aynı zamanda gaz kromatografinin sülfit monitörüne göre daha hassas dolayısıyla daha doğru teşhis verdiğini ifade etmişlerdir.

Gaz Kromatografisi ve Kütle Spektroskopisi (GC-MS): Hastaların ağız havasındaki sülfür bileşiklerinin konsantrasyonlarının belirlenmesinde kullanılır. Bu ölçüm için deneyimli personel gereklidir ve oldukça pahalı bir yöntemdir. Yapılan çalışmalarda bu yöntemle çoğu endojen ya da ağız içi kaynaklı 14 bileşik tespit edilmiştir. ${ }^{48}$

Tablo 5. Tespit Edilen 14 Volatil Sülfür Bileşiği(VSB) ${ }^{48}$

\begin{tabular}{|l|l|}
\hline Acetone & 2-Butanone \\
\hline 2-Pentanone & Indole \\
\hline Skatole & Dimethyl selenide \\
\hline 1-Propanol & Dimethyl sulfide \\
\hline Dimethyl disulfide & Dimethyl trisulfide \\
\hline Allyl methyl sulfide & Carbon disulfide \\
\hline Hydrogen sulfide & Methyl mercaptane \\
\hline
\end{tabular}

Sülfit Monitörü: İlk kez 1991'de Rosenberg ve arkadaşları tarafından geliştirilmiştir. Bu elektrokimyasal VSB (Volatil Sülfür Bileşikleri) dedektörü 01000 ppb aralığında ölçüme imkan sağlayan bir sensöre sahiptir. Kompleks gaz kromatografiye göre daha ucuzdur, kullanımı ve taşıması daha kolaydır.

Bu 3 ana metodun dışında da teşhis yöntemleri araştırılmıştır. Closed-Loop Trapping ve HighResolution Gas Chromatography-Ion Detection tekniği ile tükürük ve dili kaplayan materyaldeki bileşiklerden koku ölçme teknikleri geliştirilmiştir. ${ }^{1}$ Taşınabilir sülfid ölçerler (Halimeter-Interscan Corporation, Chatsworth,

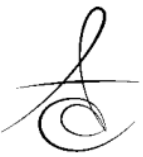


CA) çok yaygın olarak kullanılmaktadır. ${ }^{46}$ Son dönem bilgilerine göre kükürt monitörlerinden OralChroma (CHM-1) daha çok araştırma ortamlarında kullanıma uygunken, Halimeter ve Breathtron'un günlük kullanımı daha kolaydır. ${ }^{47}$ Buna ek olarak elektronik burunlar da mevcuttur. Elektronik burun elde taşınabilir bir alettir. Bilinmeyen hava içindeki kimyasalları sınıflandırmak için geliştirilmiştir. Ancak eğitilmiş personelce uygulanabilir ve henüz ucuz bir teknoloji değildir. BANA testinde ise tükürük örnekleri veya dilin kazınması ile elde edilen depozitlere uygulanan ayıraç bantta oluşan renk değişiklikleri mikroorganizma varlığına işarettir. Koyu mavi:2, açık mavi:1 ve renk değişimi olmaması:0 olarak puanlandırılır. Bu testte genellikle T. denticola, P. gingivalis ve B. forsythus mikroorganizmaları tespit edilmektedir. ${ }^{49}$

Rodriguez-Fernandez ve arkadaşları ${ }^{50}$ ağız boşluğundaki sülfit bileşiklerinin ölçülmesi için florimetrik sensör geliştirmişlerdir. Hatta bu metodun Halimeter gibi ticari sistemlere alternatif olabileceğini ileri sürmüşlerdir. Shimura ve arkadaşları ${ }^{45}$ geliştirdikleri çinko oksit semikondüktör sensörlü VSB monitörünün halitozisin teşhisinde kullanılabilirliğini göstermişlerdir. Şiddetli ağız kokusuna sahip hastalarda organoleptik değerlendirme ile karşılaştırma yapıp yüksek korelasyon buldukları için bu monitörün de rutin klinik çaışmalarda ve ağız-diş taramalarında faydalı olacağını ifade etmişlerdir. Han ve arkadaşları ${ }^{51}$ dedektör olarak yüksek sensitiviteli indium oksit semikondüktör gaz sensörü kullanan taşınabilir bir GC sistemi geliştirmişlerdir. Amano ve arkadaşları ${ }^{10}$ amonyak monitörü ile VSB arasında önemli bir ilişki bulmuşlardır.

Son dönemdeki güncel araştırmalara göre ışık kaynaklı floresans dijital (QLF-D) ile elde edilen dil kaplama görüntüleriyle kötü kokuda teşhis ve klinikte şiddet değerlendirmesi yapılabilir. Bu araştırmalarda QLF-D (Quantitative Light-induced FluorescenceDigital) ile organoleptik puan ve uçucu kükürt seviyeleri karşılaştırılmıştır ve aralarında yüksek derecede ilişki bulunmuştur. ${ }^{52}$ Otofloresans teşhis yöntemine örnek olarak VELscope cihazı, ağız kokusu teşhisi için uygun bir alettir. ${ }^{53}$

\section{HALİTOzísíN TEDAVİsí}

Temel tedavi şekli oral floranın bilhassa da anaerobların azaltılmasıdır. Ağız kokusunun kaynağına yönelik tedaviye öncelik verilmelidir. Ağız kokusunu önlemede multidisipliner yaklaşım önemlidir. ${ }^{19}$ Halitozis tedavisinde en iyi yol hastaların iyi bir oral hijyene kavuşturulmasıdır ve dentisyonun uygun şekilde olmasını sağlamaktır. ${ }^{54}$ Bunun için de çeşitli çinkolu diş macunları, dil temizleyicileri, gargaralar, çikletler, çiğneme tabletleri, yapay tükürük preparatları ve spreylerden oluşan pek çok ürün tedavi amaçlı olarak satılmaktadır. ${ }^{15,55}$ Her hastanın ağız hijyeni ve bu konudaki motivasyonu farklıdır. Halitozisten şikâyetçi olan hastalarda olabildiğince ağız hijyeni motivasyonu sağlanmalı ve bu konuda teşvik edici olunmalıdır. Telefonla yapılan bir ankette ABD'de yaşayan erkeklerin \%50'si, kadınların \%60'ı "nefes rahatlatıcı" ürünlerden kullandıkları gösterilmiştir. ${ }^{7}$ Ayrıca bütün çinko bileşiklerinin önemli derecelerde VSB blokajı yaptığı kesin olarak gösterilmiştir. ${ }^{56}$ Ağız kokusunun tedavisinde en çok çalışılan antimikrobiyal ajan klorheksidindir. Klorheksidinin çeşitli yan etkileri olsa bile klinik olarak etkili olduğu ve ağız kokusunu azalttığı belirlenmiştir. ${ }^{57}$ Çeşitli kimyasallara karşı alerjisi olan hastalar için klorheksidin tercih edilen bir tedavi yöntemi değildir.

Oral aktiviteler, tükürük akışını stimüle ederek ağızdaki VSB üreten bakterilerin sayısını azaltmaktadır. Yemek, ağız kokusu üretimini engelleyen bir faktör olarak tanımlanmış olan pH düşüşünü sağladığı için, VSB değerleri yeme-içme gibi oral aktivitelerden sonra belirgin şekilde düşmektedir. ${ }^{58}$

Amou ve arkadaşlarının ${ }^{59}$ yaptıkları çalışmada oral malodorlu hastalardan aldıkları tükürük ve dil örtüsü örneklerinde oral malodor ile ağız bakterileri arasındaki ilişkiyi incelemişler ve dil temizliğinin oral malodor üzerindeki etkisini değerlendirmişlerdir. Çalışmada, periodontal hastalık ve dil örtüsünde yer alan oral bakterilerin oral malodorla yakın ilişkili olduğu ve dil temizliğinin oral malodoru azaltmada etkili bir yöntem olabileceği sonucuna varılmıştır.

Van Der Sleen ve arkadaşlarının ${ }^{60}$ yaptığı sistematik bir derlemede dil temizlemenin çeşitli parametreler yönünden ağız kokusunu azaltmadaki etkinliğini incelemişlerdir. Çalışmanın sonucunda dilin fırçalanarak, üstünün ve sırtının temizlenmesiyle VSB seviyesini azaltarak oral malodorun başarılı bir şekilde azaldığı gözlenmiştir. Bununla birlikte kronik oral malodor hastalarında sadece dil temizliği yapılması yeterli olmamaktadır. ${ }^{61}$

Dilin fırçalanması ağız kokusunu azaltmada diş fırçalamaktan iki kat fazla etkilidir. Diş ve dil temizliğinden sonra ağız havasında hidrojen sülfit ve metil

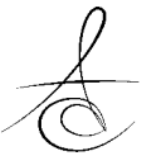


merkaptan konsantrasyonu \%25-75 oranında azalmaktadır. Dil temizlemenin önemi ile ilgili yapılan bir çalışmada VSB düzeylerinin düşürülmesinde diş fırçalamanın etkisi \%33, dil kazıyıcılarının etkisi \%40, dil temizlemenin etkisi \%42 bulunmuştur. ${ }^{49,62}$ Dil temizleyicileri el manipülasyonu gerektirse ve hasta uyumunu zorlaştırsa da tam ağız hijyeni sağlamada kullanılmalıdırlar.

Gözde Derindağ: ORCID ID: 0000-0003-0147-1798 Özkan Miloğlu: ORCID ID: 0000-0002-3826-8606

Elif Kurtuldu: ORCID ID: 0000-0003-4844-4906

Alper Özdoğan: ORCID ID: 0000-0003-0649-3056

\section{KAYNAKLAR}

1. Rosenberg M, McCulloch CAG. Measurement of oral malodor: Current methods and future prospects. J Periodontol 1992; 63: 776-82.

2. Yeagaki K, Coil JM. Genuine halitosis, pseudohalitosis and halitophobia: Classification, diagnosis and treatment. Compendium 2000; 21 : 880-9.

3. Schmidt J, Krause F, Haak R. Halitosis: measurement in daily practice. Quintessence Int 2015; 46: 633-41.

4. Akaji EA, Folaranmi N, Ashiwaju O. Halitosis: A reivew of the literature on its prevalence, impact and control. Oral Health Prev Dent 2014; 4: 297 304.

5. Morita M, Wang HL. Association between oral malodor and adult periodontitis: A review. J Clin Periodontol 2001; 28: 813-9.

6. Oho T, Yoshida Y, Shimazaki Y, Yamashita Y, Koga T. Psychological condition of patients complaining of halitosis. J Dent 2001; 29: 31-3.

7. Sanz M, Roldan S, Herrera D. Fundamentals of breath malodour. J Contemp Dent Pract 2001; 2: 1-12.

8. Lu DP. Halitosis: an etiologic classification, a treatment approach, and prevention. Oral Surg Oral Med Oral Pathol 1982; 54: 521-6.

9. Madhushankari GS, Yamunadevi A, Selvamani M, Mohan Kumar KP, Basandi PS. Halitosis - An overview: Part-I - Classification, etiology and pathophysiology of halitosis. J Pharm Bioallied Sci 2015; 7: 339-43.

10. Amano A, Yoshida Y, Oho T, Koga T. Monitoring ammonia to assess halitosis. Oral Surg Oral Med Oral Pathol Oral Radiol Endod 2002; 94: 692-6.
11. Miyazaki H, Arao M, Okamura K, Kawaguchi $Y$, Toyofuku A, Hoshi K, Yaegaki K. Tentative classification of halitosis and its treatment needs. Niigata Dental Journal 1999; 32: 7-11.

12. Tangerman A, Winkel EG. Extra-oral halitosis: an overview. J Breath Res 2010; 4: 017003.

13. Aydin M, Harvey-Woodworth CN. Halitosis: A new definition and classification. British Dent J 2014; 217: E1.

14. Replogle WH, Beebe DK. Halitosis. Am Fam Physician 1996; 53: 1215-23.

15. Suarez FL, Furne JK, Springfield J, Levitt MD. Morning breath odor: Influence of treatments on sulfur gases. J Dent Res 2000; 79: 1773-7.

16. Dudzik A, Chomyszyn-Gajewska M. Pseudohalitosis and halitophobia. Przegl Lek 2014; 71: 274-6.

17. Aydın M. Ağız Kokusu Teşhisi ve Tedavisi. Dentalife 2005; 14: 26-9.

18. Ben-Aryeh H, Horowitz G, Nir D, Laufer D. Halitosis: An interdisciplinary approach. Am J Otolaryngol 1998; 19: 8-11.

19. Mokeem SA. Halitosis: a review of the etiologic factors and association with systemic conditions and its management. J Contemp Dent Pract 2014; 15: 806-11.

20. Delanghe G, Ghyselen J, Bollen C, van Steenberghe D, Vandekerckhove BN, Feenstra L. An inventory of patients_response to treatment at a multidisciplinary breath odor clinic. Quintessence Int 1999; 30: 307-10.

21. Scully C, Porter R, Greenman J. What to do about halitosis? British Med J 1994; 308: 217-8.

22. Yaegaki K, Sanada K. Volatile sulfur compounds in mouth air from clinically healthy subjects and patients with periodontal disease. J Periodontal Res 1992: 27: 233-8.

23. Lang B, Filippi A. Halitosis-Part 1: Epidemiology and pathogenesis. Schweiz Monatsschr Zahnmed 2004; 114: 1037-50.

24. Zigurs G, Vidzis A, Brinkmane A. Halitosis Manifestation and prevention means for patients with fixed teeth dentures. Stomatologia 2005; 7: 3-6.

25. Young K, Oxtoby A, Field EA. Halitosis: A review. Dent Update 1993; 20: 57-61. 
26. Rosenberg M. Clinical assessment of bad breath: current concepts. J Am Dent Assoc 1996; 127: 475-82.

27. Delanghe G, Ghyselen J, Feenstra L, Van Steenberghe D. Multidisciplinary breath-odour clinic. Leuven, Belgium: Leuven University Press 1996: 199-208.

28. Ierardi $E$, Amoruso A, La Notte $T$, Francavilla $R$, Castellaneta S, Marrazza $E$, et al. Halitosis and Helicobacter pylori: A possible relationship. Dig Dis Sci 1998; 43: 2733-7.

29. Yilmaz $A E$, Bilici $M$, Tonbul $A$, Karabel M, Dogan G, Tas T. Paediatric halitosis and Helicobacter pylori infection. J Coll Physicians Surg Pak 2012; 22: 27-30.

30. Vali A, Roohafza $H$, Keshteli AH, Afghari $P$, Javad Shirani M, Afshar $H$, et al. Relationship between subjective halitosis and psy chological factors. Int Dent J 2015; 65: 120-6.

31. Kleinberg I, Westbay G. Salivary metabolic factors and involved in oral malodor formation. J Periodontol 1992; 63: 768-75.

32. Berg M, Fosdick LS. Studies in Periodontal disease. II. Putrefactive organisms in the mouth. J Dent Res 1946; 25: 73-81.

33. Singh VP, Malhotra N, Apratim A, Verma M. Assessment and management of halitosis. Dent Update 2015; 42: 346-53.

34. Ratcliff PA, Johnson PW. The relationship between oral malodor, gingivitis and periodontitis. A review. J Periodontol 1999; 70: 485-9.

35. Young A, Jonski G, Rölla G, Waler SM. Effects of metal salts on the oral production of volatile sulfur-containing compounds (VSC). J Clin Periodontol 2001; 28: 776-81.

36. Waler S. On the transformation of sulfurcontaining amino acids and peptides to volatile sulfur compounds (VSC) in the human mouth. Eur J Oral Sci 1997; 105: 534-7.

37. Kojima K. Clinical studies on the coated tongue. Jpn J Oral Maxillofac Surg 1985: 1659-76.

38. Oho T, Yoshida $Y$, Shimazaki $Y$, Yamashita $Y$, Koga T. Characteristics of patients complaining of halitosis and the usefulness of gas chromatography for diagnosing halitosis. Oral Surg Oral Med Oral Pathol Oral Radiol Endod 2001; 91: 531-4.
39. Masuo $Y$, Suzuki N, Yoneda M, Naito T, Hirofuji $T$. Salivary $\beta$-galactosidase activity affects physiological oral malodour. Arch Oral Biol 2012; 57: 87-93.

40. Yaegaki K, Sanada K. Biochemical and clinical factors influencing oral malodor in periodontal patients. J Periodontol 1992; 63: 783-9.

41. De Boevcr EH, Loesche WJ. Assessing the contribution of anaerobic microflora of the tongue to oral malodor. J Am Dent Assoc 1995; 126: 1384-93.

42. McNamara TF, Alexander JF, Lee M. The role of microorganisms in the production of oral malodor. Oral Surg 1972; 34: 41.

43. Yang F, Huang S, He T, Catrenich C, Teng F, Bo $C$, et al. Microbial basis of ora malodor development in humans. J Dent Res 2013; 92: 1106-12.

44. Goldberg S, Cardash H, Browning III, Sahly H, Rosenberg $M$. Isolation of enterobacteriacaeae from the mouth and potential association with malodor. J Dent Res 1997; 76: 1770-5.

45. Shimura $M$, Watanabe $S$, Iwakura M, Oshikiri $Y$, Kusumoto $M$, Ikawa $K$, et al. Correlation between measurements using a new halitosis monitor and organoleptic assessment. J Periodontol 1997; 8: 1182-5.

46. Rosenberg M, Kulkarni GV, Bosy A, McCulloch CAG. Reproducibility and sensitivity of oral malodor measurements with a portable sulfide monitor. J Dent Res 1991; 11: 1436-40.

47. Laleman I, Dadamio J, De Geest S, Dekeyser C, Quirynen M. Instrumental assessment of halitosis for the general dental practitioner. J Breath Res 2014; 8: 017103.

48. Van den Velde S, Quirynen M, van Hee P, van Steenberghe D. Halitosis associated volatiles in breath of healthy subjects. J Chromatography B Analytical Technologies Biomed Life Sci 2007; 853: 54-61.

49. Aylıkc BU, Colak H. Halitosis: From diagnosis to management. J Nat Sci Biol Med 2013; 4: 14-23.

50. Rodriguez-Fernandez J, Costa JM, Pereiro R, Sanz-Medel A. Simple detector for oral malodour based on spectrofluorimetric measurements of hydrogen sulphide in mouth air. Anal Chim Acta 1999; 398: 23-31. 
51. Hanada M, Koda H, Onaga K, Tanaka K, Okabayashi $\mathrm{T}$, Itoh $\mathrm{T}$, et al. Portable oral malodor analyser using highly sensitive $\mathrm{In}_{2} \mathrm{O}_{3}$ gas sensor combined with a simple gas chromatography system. Anal Chim Acta 2003; 475: 27-35.

52. Lee ES, Yim HK, Lee HS, Choi JH, Kwon HK, Kim BI. Clinical assessment of oral malodor using autofluorescence of tongue coating. Photodiagnosis Photodyn Ther. 2016 Mar; 13: 323-9.

53. Hitz Lindenmüller $I$, Weiss $P$, Volken $M$, Filippi $A$. Diagnostics of tongue coating using autofluorescence. Swiss Dent J 2015; 125: 1074.

54. Rosenberg M. Bad Breath: Diagnosis and treatment. Univ Tor Dent J 1990; 3: 7-11.

55. Scully C. Halitosis. BMJ Clin Evid 2014. pii: 1305.

56. Murata T, Yamaga T, Lida T. Classification and examination of halitosis. Int Dent $\mathrm{J} 2002$; 52: 181-6.

57. Roldán S, Herrera D, O'Connor A, González I, Sanz M. A combined therapeutic approach to manage oral halitosis: a 3-month prospective case series. J Periodontol 2005; 76: 1025-33.

58. Quirynen M, Zhao $H$, Soers C, Dekeyser C, Pauwels $M$, Coucke $W$, et al. The impact of periodontal therapy and the adjunctive effect of antiseptics on breath odorrelated outcome variables: A double-blind randomized study. J Periodontol 2005; 76: 705-12.

59. Amou T, Hinode D, Yoshioka M, Grenier D. Relationship between halitosis and periodontal disease-associated oral bacteria in tongue coatings. Int J Dent Hygiene 2013; 6: 1-7.

60. Van Der Sleen MI, Slot DE, Van Trijffel E, Winkel EG, Van Der Weijden GA. Effectiveness of mechanical tongue cleaning on breath odour and tongue coating: A systematic review. Int J Dental Hygiene 2010; 8: 258-68.

61. Pitts G, Brogdon C, Hu L, Masurat T, Pianotti R, Schumann P. Mechanism of action of an antiseptic, anti-odor mouthwash. J Dent Res 1983; 62: 738-42.

62. Seemann R, Kison A, Bizhang M, Zimmer S. Effectiveness of mechanical tongue cleaning on oral levels of volatile sülfür compounds. J Am Dent Assoc 2001; 132: 1263-7.

\section{Yazışma Adresi}

Dr. Özkan MİLOĞLU, Atatürk Üniversitesi, Diş Hekimliği Fakültesi, Ağız, Diş ve Çene Radyolojisi A.D., Erzurum, Türkiye

İş Telefonu: +90 4422311778

Faks Numarası: +90 4422360945

Mail adresi: omiloglu@hotmail.com 